\title{
Gastrointestinal symptoms in morbid obesity
}

\author{
Mustafa Huseini ${ }^{1}$, G. Craig Wood ${ }^{1}$, Jamie Seiler ${ }^{1}$, George Argyropoulos ${ }^{1}$, Brian A. Irving ${ }^{1}$, \\ Glenn S. Gerhard ${ }^{1,2}$, Peter Benotti ${ }^{1}$, Christopher Still ${ }^{1}$ and David D. K. Rolston ${ }^{1,3} *$ \\ 1 Institute of Obesity, Geisinger Health System, Danville, PA, USA \\ 2 Department of Biochemistry, Molecular Biology, Pathology and Laboratory Medicine, Pennsylvania State University, Hershey, PA, USA \\ ${ }^{3}$ Department of Internal Medicine, Geisinger Health System, Danville, PA, USA
}

\section{Edited by:}

Yeong Yeh Lee, Universiti Sains

Malaysia, Malaysia

Reviewed by:

Katsunori lijima, Tohoku University Graduate School of Medicine, Japan Alejandro Piscoya, Universidad Peruana de Ciencias Aplicadas, Peru Rossella Cianci, Cattolic University of Sacred Heart, Italy

*Correspondence:

David D. K. Rolston, Geisinger

Medical Center MC 14-01, 100 North

Academy Avenue, Danville, PA 17822,

USA

e-mail:ddrolston@geisnger.edu

\begin{abstract}
Background: Several reports have shown an increased prevalence of gastrointestinal (GI) symptoms in obese subjects in community-based studies. To better understand the role of the Gl tract in obesity, and because there are limited clinic-based studies, we documented the prevalence of upper and lower Gl symptoms in morbidly obese individuals in a clinic setting.
\end{abstract}

Objective:The aim of our study was to compare the prevalence of Gl symptoms in morbidly obese individuals in a weight management clinic with non-obese individuals with similar comorbidities as morbidly obese individuals in an Internal Medicine clinic.

Methods: Class II and III obese patients BMI $>35 \mathrm{~kg} / \mathrm{m}^{2}(N=114)$ and 182 non-obese patients $\left(\mathrm{BMI}<25 \mathrm{~kg} / \mathrm{m}^{2}\right.$ ) completed the $\mathrm{Gl}$ symptoms survey between August 2011 and April 2012 were included in this study. The survey included 24 items pertaining to upper and lower Gl symptoms. The participants rated the frequency of symptoms as absent (never, rarely) or present (occasionally, frequently). The symptoms were clustered into five categories: oral symptoms, dysphagia, gastroesophageal reflux, abdominal pain, and bowel habits. Responses to each symptom cluster were compared between obese group and normal weight groups using logistic regression.

Results: Of the 24 items, 18 had a higher frequency in the obese group ( $p<0.005$ for each). After adjusting for age and gender, the obese patients were more likely to have upper GI symptoms: any oral symptom (OR $=2.3, p=0.0013)$, dysphagia (OR 2.9, $p=0.0006)$, and any gastroesophageal reflux (OR 3.8, $p<0.0001$ ). Similarly, the obese patients were more likely to have lower $\mathrm{Gl}$ symptoms: any abdominal pain $(\mathrm{OR}=1.7, p=0.042)$ and altered bowel habits (OR $=2.8, p<0.0001)$.

Conclusion: These observations suggest a statistically significant increase in frequency of both upper and lower Gl symptoms in morbidly obese patients when compared to non-obese subjects.

Keywords: obesity, gastrointestinal, symptoms, body mass index, clinic-based studies

\section{INTRODUCTION}

The obesity epidemic continues unabated world-wide. The increasing prevalence of overweight and obesity has resulted in 3.4 million deaths, $3.9 \%$ of years lost, and $3.8 \%$ of disability adjusted life-years world-wide. Greater than $50 \%$ of obese individuals reside in the USA, China, India, Russia, Brazil, Egypt, Germany, Pakistan, and Indonesia (1). The USA accounted for $13 \%$ of these obese individuals in 2013. Obesity trends in the USA along with associated comorbidities could, for the first time result in decreased life expectancy (2). The Centers for Disease Control, National Center for Health Statistics in the USA, has estimated that, between 2011 and 2012, more than one-third of adults $(34.9 \%)$ were obese and that two-thirds of the US population is overweight or obese (3). The burden of obesity and its associated health problems have a significant adverse impact on the US healthcare system. In 2008, the annual healthcare cost in the US was estimated to be a staggering \$ 147 billion (4). Besides cost, obesity results in 100,000 excess deaths per annum (5) and estimated years of life lost (difference between the number of years an individual would live if not obese and the number of years expected to live if obese) was estimated to be 13 years for white men aged 20 years with BMI $>45 \mathrm{~kg} / \mathrm{m}^{2}$ and 8 years for white women aged $20-30$ years with BMI $>45 \mathrm{~kg} / \mathrm{m}^{2}$ compared to normal weight controls (6).

The gastrointestinal (GI) tract is normally the only site of nutrient and calorie absorption. Improved understanding of the role of the GI tract in obesity may help develop strategies to decrease obesity and obesity-related health costs. Because there are limited clinic-based studies, in contrast to population-based studies, we documented the prevalence of upper and lower GI symptoms in morbidly obese individuals attending the Obesity Institute outpatient clinic and normal weight individuals with similar comorbidities attending the General Internal Medicine (GIM) clinic at the Geisinger Medical Center in Danville, PA, USA. 


\section{SUBJECTS AND METHODS}

This study included morbidly obese patients (BMI $>35 \mathrm{~kg} / \mathrm{m}^{2}$ ) with metabolic comorbidities or BMI $>40 \mathrm{~kg} / \mathrm{m}^{2}$ and normal weight patients (BMI $18.5-24.9 \mathrm{~kg} / \mathrm{m}^{2}$ ) who sought care at Geisinger Medical Center, Danville, PA, USA. All potential study subjects were asked to complete the GI Symptoms survey, which was developed by the study team to address the frequency of GI symptoms. The questionnaire included 24 items and was formulated via literature review, review of gastroenterology textbooks and incorporated the Rome II and III questionnaires. The patients rated the frequency of symptoms as "Never, Rarely, Occasionally, and Frequently" (Table 1). The symptoms were categorized into the following five clusters: (1) oral symptoms - mouth ulcers, bleeding gums, dental problems, tongue swelling, sour taste; (2) dysphagia - gagging, trouble swallowing solids or liquids; (3) reflux - sour taste, nausea, vomiting, heartburn, belching/burping; (4) abdominal pain - cramping with hunger or post-meal; (5) bowel habits - diarrhea, fecal urgency and incontinence, bloating, constipation, excessive flatus, use of laxatives, rectal bleeding.

The obese study group included patients with extreme obesity that agreed to participate in a separate, ongoing research study of bariatric surgery within the Nutrition and Weight Management Clinic of the Obesity Institute (7). Consecutive patients that completed the GI Symptoms survey between August 2011 and April 2012 were included in this research study $(N=114)$. During the same time period, non-obese patients were recruited from the GIM clinic. For this study group, potential participants were identified by querying the Geisinger electronic health record for patient's seen in the GIM clinic in the preceding 1 year with a BMI $18.5-25 \mathrm{~kg} / \mathrm{m}^{2}$. The study population was limited to those aged 18-64 years in both groups. Patients with a prior history of intra-abdominal surgery, inflammatory bowel disease, any acute infectious processes, and patients using orlistat were excluded from the study. The eligible normal weight patients with comorbidities similar to the obese group $(N=652)$ were mailed a packet that included an introduction letter, the GI Symptoms survey, and a pre-addressed, pre-paid return envelope. Four patient letters were returned due to wrong address. Of the remaining 648 patients, 140 returned the survey within 6 weeks. The remaining patients were sent a second packet with a revised introduction letter and the same survey and envelope. This resulted in an additional 42 completed surveys, and an overall total of 182 normal weight participants (overall completion rate of $28 \%$ ).

Responses to each symptom question were compared between the normal weight and obese group using Cochran-Armitage trend tests. For each of the five symptom domain groups, patients were classified as having any symptom within the group (defined as "Occasionally" or "Frequently" for any of the questions within the symptom domain group) or no symptoms (defined as "Never" or "Rarely" for all of the questions within the symptom group). In bivariate analysis, the percent of patients with any symptom was compared between the normal weight and obese groups using a chi-square test. In multivariate analysis (adjusting for age and gender), logistic regression was used to measure the association between the presence of any symptom and obesity status. Separate regression models were used for each symptom group. To confirm that categorizing the likert scaled response items into present (i.e., "Occasionally" or "Frequently") or absent (i.e., "Never" or "Rarely") did not influence the results, the data were reanalyzed using the likert scale for each question. The categorized version is presented because these simpler results agreed with the more complex analysis. SAS version 9.3 was used for statistical analysis and a $p$-value $<0.05$ was considered significant.

Funding for this study was provided through Geisinger internal funds. The Geisinger Institutional Research Review Board approved the study.

\section{RESULTS}

The 182 normal weight patients had a mean BMI of $22.1 \mathrm{~kg} / \mathrm{m}^{2}$ $(\mathrm{SD}=1.7)$, a mean age of 50.8 years $(\mathrm{SD}=11.1)$, and $78 \%$ were female (Table 2). As compared to the 470 non-responders, the 182 normal weight patients that responded to the survey were older ( 50.8 years versus 45.0 years, $p<0.0001$ ) and more likely to be female ( 78 versus $70 \%$ female, $p=0.040$ ). The 114 class II obese patients had a mean BMI of $50.1 \mathrm{~kg} / \mathrm{m}^{2}(\mathrm{SD}=10.0$, range: $\left.35.0 \mathrm{~kg} / \mathrm{m}^{2}-78.3 \mathrm{~kg} / \mathrm{m}^{2}\right)$, a mean age of 44 years $(\mathrm{SD}=10.8)$, and $79 \%$ were female.

Of the 24 individual symptom questions, 18 had a higher frequency in the class II and III obesity group as compared to the normal weight group ( $p<0.05$, Table 1). Significant associations were found for three of the five oral symptom questions, two of the three dysphagia questions, four of the five reflux questions, both of the abdominal pain questions, and seven of the nine bowel habits questions.

When combining questions into symptom groups, the prevalence of any symptom within each of the five groups was higher in the class II obese group (Figure 1). Oral symptoms were present in $57 \%$ of the obese group versus $38 \%$ of the normal weight patients $(p=0.0016)$. Dysphagia symptoms were present in $32 \%$ of the obese group versus $17 \%$ in those with normal weight $(p=0.0038)$. Reflux was significantly higher in obese patients compared to normal weight patients ( 79 versus $48 \%, p<0.0001$ ). Forty percent of the obese subjects experienced abdominal pain symptoms as compared to $25 \%$ of the normal weight patients $(p=0.0088)$. Finally, altered bowel habits were more common in the obese group (82\%) as compared to the normal weight group $(61 \%, p<0.0001)$.

After adjusting for age and gender, the prevalence of symptoms remained higher in the class II obese group for all of the symptom groups (Table 3). Those in the obese group were 2.28 times more likely to have oral symptoms $[95 \% \mathrm{CI}=(1.38,3.78), p=0.0013]$, 2.90 times more likely to have dysphagia $[95 \% \mathrm{CI}=(1.58,5.33)$, $p=0.0006], 3.77$ times more likely to have reflux $[95 \% \mathrm{CI}=(2.16$, 6.59), $p<0.0001], 1.73$ times more likely to have abdominal pain $[95 \% \mathrm{CI}=(1.02,2.94), p=0.042]$, and 2.79 times more likely to have altered bowel habits $[95 \% \mathrm{CI}=(1.55,5.01), p<0.0001]$.

\section{DISCUSSION}

Both population-based (8-10) and hospital- or office-based (11, 12) studies have demonstrated an increase in the prevalence of GI symptoms in obese individuals. The most extensively studied are esophageal symptoms, which include gastroesophageal reflux (often used interchangeably with heartburn), which also occurs in approximately $40 \%$ of individuals in the general population (13). Other esophageal symptoms include the regurgitation of solids or 
Table 1 | GI symptom survey responses by symptom category (114 obese patients and 182 normal weight patients).

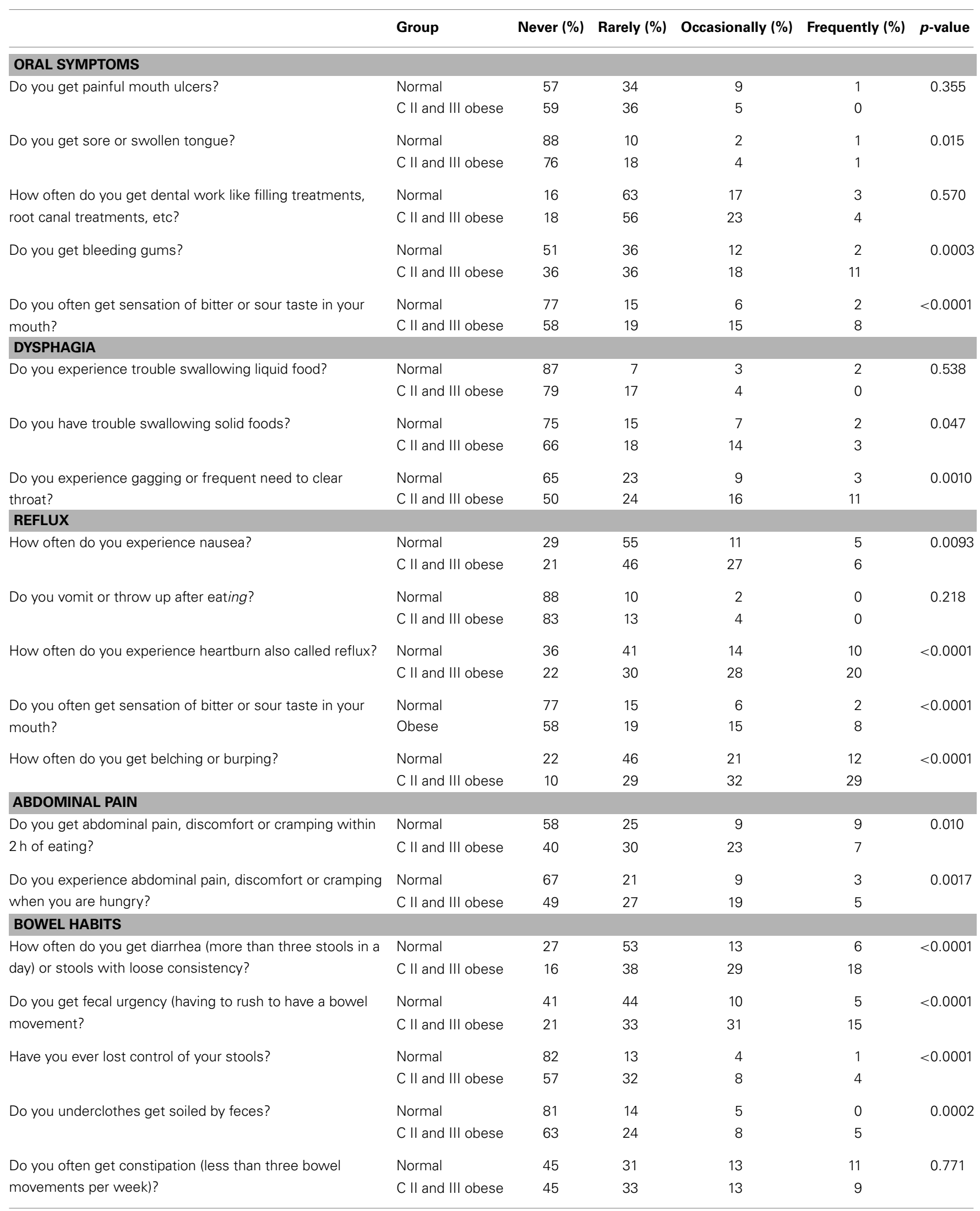


Table 1 | Continued

\begin{tabular}{|c|c|c|c|c|c|c|}
\hline & Group & Never (\%) & Rarely (\%) & Occasionally (\%) & Frequently (\%) & $p$-value \\
\hline \multirow[t]{2}{*}{ Do you get abdominal bloating? } & Normal & 35 & 38 & 14 & 13 & 0.0014 \\
\hline & C II and III obese & 22 & 28 & 35 & 15 & \\
\hline \multirow[t]{2}{*}{ How often have you had rectal bleeding in last 1 year? } & Normal & 74 & 18 & 6 & 2 & 0.0014 \\
\hline & C II and III obese & 58 & 19 & 19 & 3 & \\
\hline \multirow[t]{2}{*}{ Do you pass excessive flatus? } & Normal & 28 & 36 & 21 & 15 & 0.0005 \\
\hline & C II and III obese & 15 & 28 & 31 & 26 & \\
\hline \multirow[t]{2}{*}{ How would you rate your use of laxatives or enema? } & Normal & 82 & 13 & 4 & 1 & 0.724 \\
\hline & C II and III obese & 85 & 10 & 2 & 3 & \\
\hline
\end{tabular}

Table 2 | Description of the normal weight and obese study populations.

\begin{tabular}{llcc}
\hline & & $\begin{array}{c}\text { Normal weight } \\
\boldsymbol{N}=\mathbf{1 8 2}\end{array}$ & $\begin{array}{c}\text { Class II and III obese } \\
\boldsymbol{N}=\mathbf{1 1 4}\end{array}$ \\
\hline \multirow{2}{*}{ Gender } & Male & $22 \%(n=40)$ & $21 \%(n=24)$ \\
& Female & $78 \%(n=142)$ & $79 \%(n=90)$ \\
Age & Mean (SD) & $50.8(11.1)$ & $44.0(10.8)$ \\
& Range (min, max) & $(20,64)$ & $(19,64)$ \\
BMI & Mean (SD) & $22.1(1.7)$ & $50.1(10.0)$ \\
& Range (min, max) & $(18.5,25.0)$ & $(35.0,78.3)$
\end{tabular}

sour liquids, globus, chest pain, dysphagia, dry cough, and throat pain (8). Our study, which comprised morbidly obese individuals (mean BMI $>50 \mathrm{~kg} / \mathrm{m}^{2}$ ), confirms these findings. This is not surprising since individuals with a $\mathrm{BMI}>30 \mathrm{~kg} / \mathrm{m}^{2}$ have a threefold increase in the odds of having reflux symptoms (14). This finding has been confirmed repeatedly including in the recent Progression of Gastroesophageal Reflux Disease study, which demonstrated that there was increased severe heartburn, regurgitation, and esophagitis with higher BMI, with regurgitation being more frequent than heartburn (15) and in two meta-analyses $(16,17)$. There was a trend toward greater GERD symptoms in individuals with a BMI $>30 \mathrm{~kg} / \mathrm{m}^{2}$ (pooled adjusted odds ratio of $1.94 \mathrm{com}$ pared to1.43 for individuals with a BMI of $25-30 \mathrm{~kg} / \mathrm{m}^{2}$ ) when GERD was diagnosed by a validated questionnaire or endoscopy findings (16). Not only is heartburn more common in the obese individual (32.6 versus $18.8 \%$ in normal weight controls) so is endoscopic evidence of hiatal hernia and gastritis (11). In contrast, in massive obesity no association with heartburn was found (18).

The mechanism of upper GERD symptoms in obesity remains conjectural partly because there are limited studies addressing this (13). While basal lower esophageal sphincter (LES) pressure is similar in morbidly obese individuals and normal weight individuals (19), the frequency of transient lower esophageal sphincter relaxation (TLESR) is increased with increasing BMI and waist circumference (20), suggesting that waist circumference plays a role in GERD in obesity. Additionally, increased intra-abdominal pressure (21), increased gastroesophageal pressure gradient, hiatal hernia (11), altered visceral sensitivity and increased gastric basal pressure (22) all probably play a variable role. We did not evaluate the effect of weight circumference and waist to hip ratio in our patients.

There are less clear mechanistic studies on GI symptoms such as chest pain, bloating, and post-prandial fullness. The role that proinflammatory cytokines play in obesity, i.e., TNF- $\alpha$, IL-6, IL-1, and leptin (23) and the concomitant decrease in the pro-inflammatory cytokine, adiponectin (24) may play in esophageal contractility and increased incidence of esophagitis is unclear as is their role in gastric motility, gastritis, small and large bowel function in obesity.

It is possible that estrogens implicated in more frequent TLESRs (25) could skew the results of GERD-related symptoms in our predominantly female population ( $79 \%$ female versus $21 \%$ male in obese subjects and $78 \%$ female and $22 \%$ male in normal weight subjects) but age and gender corrected analysis of our data did not alter our results.

In keeping with published reports, our obese patients reported more frequent nausea, abdominal pain, bloating, diarrhea, and flatulence compared to normal weight individuals $(9,26)$. We did not distinguish between upper and lower abdominal pain as many patients had difficulty making this distinction. The mechanism of abdominal and bowel symptoms (Tables 1 and 3; Figure 1) is unclear and studies are few and data conflicting. It has been suggested that alteration in gastric emptying, gastric capacity, and gastric accommodation may play a role $(27,28)$. The role, if any of pro-inflammatory cytokines in abdominal pain, early satiety, flatulence, and diarrhea have not been studied. It is reasonable to assume that they do play a role in intestinal motility in general and not just in esophageal muscle contractility (23).

The prevalence of dysphagia has been reported to be approximately $10 \%$ and globus $8 \%$ in patients being evaluated for bariatric surgery (29). In our subjects, the prevalence of dysphagia to solids was $3 \%$ in obese subjects compared to $2 \%$ in normal weight individuals $(p=0.047)$. There is no obvious reason for the lower prevalence of dysphagia in our obese patients. Dysphagia to liquids, a symptom not reported in other studies, was higher in normal weight individuals although it did not reach statistical significance ( $p=0.538)$.

Obese individuals in our study had similar prevalence of constipation and laxative use as normal weight individuals. The data in the literature are conflicting with regard to constipation where 


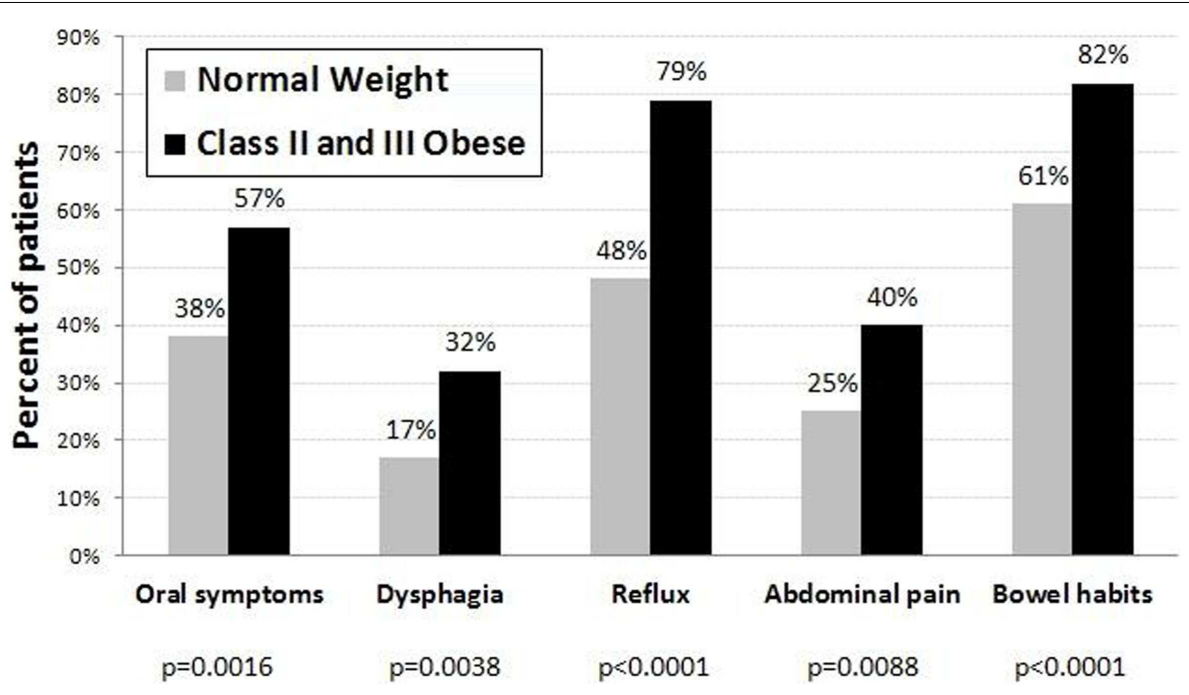

FIGURE 1 | Percent of normal weight $(N=182)$ and class II and III obese $(N=114)$ patients with occasional/frequent symptoms in each symptom group.

Table 3 | Multivariate regression results for presence of any symptom within the symptom group

\begin{tabular}{lccc}
\hline Symptom group & $\begin{array}{c}\text { Adjusted }^{\text {a }} \text { OR for } \\
\text { class II and III obesity }\end{array}$ & $\mathbf{9 5 \%}$ Cl & p-value \\
\hline Oral symptoms & 2.28 & $1.38,3.78$ & 0.0013 \\
Dysphagia & 2.90 & $1.58,5.33$ & 0.0006 \\
Reflux & 3.77 & $2.16,6.59$ & $<0.0001$ \\
Abdominal pain & 1.73 & $1.02,2.94$ & 0.042 \\
Bowel habits & 2.79 & $1.55,5.01$ & 0.0006 \\
\hline
\end{tabular}

${ }^{a}$ Adjusted for age and gender.

some studies have found no relationship between BMI and constipation (30), while others have found a higher prevalence of constipation in obese individuals (31) and those who were binge eaters (32).

Diarrhea, fecal urgency, and incontinence were more commonly reported in our obese subjects, a finding consistent with that reported in both population - as well as clinic-based studies $(9,29,33)$. Decreased colonic compliance and colonic sensation in overweight individuals and decreased transit time in those with a BMI $>30 \mathrm{~kg} / \mathrm{m}^{2}$ could play a role in the pathogenesis of these symptoms (34).

The role of nutrient-sensing mechanisms in the GI tract (taste receptors) (35), their interplay with peptides such as glucagon-like peptide one, glucagon, neuropeptide Y, peptide YY, ghrelin, and oxyntomodulin (36) among others and their effect, if any, on satiety, gut motility, nutrient absorption, gut-brain signaling via vagal afferent neurons (37), and GI symptoms are yet to be explored.

There are no previous reports of oral symptoms in obese individuals compared to normal weight individuals. A sore tongue or a sensation of a swollen tongue $(p<0.015)$ and bleeding gums $(p<0.003)$ occurred more frequently in our obese patients. The increased sensation of a bitter taste or sour taste in the mouth is consistent with "water brash," a symptom of gastroesophageal reflux, which occurs more frequently in obese individuals. The mechanism of the increased prevalence of oral symptoms could be related to micronutrient deficiencies, but this remains speculative since we did not measure any micronutrient level.

Our study has several strengths in that: (i) we were able to document the increased prevalence of GI symptoms in a clinic-based population, confirming the data on GI symptoms derived largely from population studies. (ii) We describe for the first time that oral symptoms (swollen tongue and bleeding gums) occur more frequently in obese patients. (iii) While there was a preponderance of females in our study, and females are known to have more functional bowel disease compared to males (38) even after adjusting for age and gender the results of our study do not change (Table 3 ). (iv) We did not cluster symptoms based on diagnosis so that clustering did not skew our data. For example, a higher irritable bowel syndrome score may be reflected in a higher abdominal pain score.

There are several limitations to our study: (i) we did not use validated questionnaires such as the gastroesophageal reflux questionnaire (8) or the bowel disease questionnaire (39). These questionnaires were designed to establish a diagnosis of gastroesophageal reflux or functional bowel disease in population cohorts; this was not the purpose of our study. Besides, our questionnaire did incorporate most of the questions found in the validated questionnaires. (ii) We did not evaluate anxiety and depression in our subjects. These conditions are associated with higher somatic complaints including GI symptoms. (iii) The prevalence of diabetes and vascular disease, among other chronic diseases, is higher in obesity. These diseases are known to be associated with abdominal symptoms and could have confounded our results. (iv) We did not take into account the influence of medications on GI symptoms used to treat the chronic diseases that these subjects had. (v) Our population was predominantly Caucasian, so the results of 
our study may not be generalizable to individuals of different ethnic backgrounds and possibly different food habits. (vi) A response rate of $28 \%$ in our study does not automatically imply that the frequencies are not accurate. They do have the potential to have more error but equally they could be accurate. Higher response rates of $54-68 \%$ are found in the literature in some studies. The higher response rate appears to be dependent on the level of education of the respondents. Other studies have shown a response rate of $26 \%$ for mail surveys, which is similar to the response rate in our study (40). This is in contrast to faxed and electronic surveys, which have higher response rates. It is important to bear in mind that the response rate indirectly reflects non-respondent bias. It has been suggested that more attention be paid to assessments of bias, and less to response rate (41). We therefore feel that our response rate does not detract from the validity of the study.

In conclusion, this study demonstrates that several GI symptoms are more commonly seen in obese individuals compared to normal weight individuals with similar comorbidities. Better understanding of the mechanism of these symptoms may be valuable in offering the appropriate treatment, i.e., surgical versus medical particularly as medical therapeutic options increase (36).

\section{REFERENCES}

1. Ng M, Fleming T, Robinson M, Thomson B, Graetz N, Margono C, et al. Global, regional, and national prevalence of overweight and obesity in children and adults during 1980-2013: a systematic analysis for the Global Burden of Disease Study 2013. Lancet (2014) 384(9945):766-81. doi:10.1016/S0140-6736(14) 60460-8

2. Olshansky SJ, Passaro DJ, Hershow RC, Layden J, Carnes BA, Brody J, et al. A potential decline in life expectancy in the United States in the 21st century. $N$ Engl J Med (2005) 352(11):1138-45. doi:10.1056/NEJMsr043743

3. Centers for Disease Control and Prevention (CDC). National Center for Health Statistics. NCHS Obesity Data. Available from: http://www.cdc.gov/nchs/data/ factsheets/factsheet_obesity.htm

4. Finkelstein EA, Trogdon JG, Cohen JW, Dietz W. Annual medical spending attributable to obesity: payer-and service-specific estimates. Health Aff (Millwood) (2009) 28(5):w822-31. doi:10.1377/hlthaff.28.5.w822

5. Flegal KM, Graubard BI, Williamson DF, Gail MH. Excess deaths associated with underweight, overweight, and obesity. JAMA (2005) 293(15):1861-7. doi:10.1001/jama.293.15.1861

6. Fontaine KR, Redden DT, Wang C, Westfall AO, Allison DB. Years of life lost due to obesity. JAMA (2003) 289(2):187-93. doi:10.1001/jama.289.2.187

7. Wood GC, Chu X, Manney C, Strodel W, Petrick A, Gabrielsen J, et al. An electronic health record-enabled obesity database. BMC Med Inform Decis Mak (2012) 12:45. doi:10.1186/1472-6947-12-45

8. Locke GR, Talley NJ, Weaver AL, Zinsmeister AR. A new questionnaire for gastroesophageal reflux disease. Mayo Clin Proc (1994) 69(6):539-47. doi:10.1016/ S0025-6196(12)62245-9

9. Delgado-Aros S, Locke GR III, Camilleri M, Talley NJ, Fett S, Zinsmeister $\mathrm{AR}$, et al. Obesity is associated with increased risk of gastrointestinal symptoms: a population-based study. Am J Gastroenterol (2004) 99(9):1801-6. doi:10.1111/j.1572-0241.2004.30887.x

10. Djarv T, Wikman A, Nordenstedt H, Johar A, Lagergren J, Lagergren P. Physical activity, obesity and gastroesophageal reflux disease in the general population. World J Gastroenterol (2012) 18(28):3710-4. doi:10.3748/wjg.v18.i28.3710

11. Dutta SK, Arora M, Kireet A, Bashandy H, Gandsas A. Upper gastrointestinal symptoms and associated disorders in morbidly obese patients: a prospective study. Dig Dis Sci (2009) 54(6):1243-6. doi:10.1007/s10620-008-0485-6

12. van Oijen MG, Josemanders DF, Laheij RJ, van Rossum LG, Tan AC, Jansen JB. Gastrointestinal disorders and symptoms: does body mass index matter? Neth J Med (2006) 64(2):45-9.

13. Anand G, Katz PO. Gastroesophageal reflux disease and obesity. Gastroenterol Clin North Am (2010) 39(1):39-46. doi:10.1016/j.gtc.2009.12.002
14. Locke GR III, Talley NJ, Fett SL, Zinsmeister AR, Melton LJ III. Risk factors associated with symptoms of gastroesophageal reflux. Am J Med (1999) 106(6):642-9. doi:10.1016/S0002-9343(99)00121-7

15. Nocon M, Labenz J, Jaspersen D, Meyer-Sabellek W, Stolte M, Lind T, et al. Association of body mass index with heartburn, regurgitation and esophagitis: results of the progression of gastroesophageal reflux disease study. J Gastroenterol Hepatol (2007) 22(11):1728-31. doi:10.1111/j.1440-1746.2006.04549.x

16. Hampel H, Abraham NS, El-Serag HB. Meta-analysis: obesity and the risk for gastroesophageal reflux disease and its complications. Ann Intern Med (2005) 143(3):199-211. doi:10.7326/0003-4819-143-3-200508020-00006

17. Corley DA, Kubo A. Body mass index and gastroesophageal reflux disease: a systematic review and meta-analysis. Am J Gastroenterol (2006) 101(11):2619-28. doi:10.1111/j.1572-0241.2006.00849.x

18. Lundell L, Ruth M, Sandberg N, Bove-Nielsen M. Does massive obesity promote abnormal gastroesophageal reflux? Dig Dis Sci (1995) 40(8):1632-5. doi:10.1007/BF02212682

19. O’Brien TF Jr. Lower esophageal sphincter pressure (LESP) and esophageal function in obese humans. J Clin Gastroenterol (1980) 2(2):145-8. doi:10.1097/ 00004836-198006000-00007

20. Wu JC, Mui LM, Cheung CM, Chan Y, Sung JJ. Obesity is associated with increased transient lower esophageal sphincter relaxation. Gastroenterology (2007) 132(3):883-9. doi:10.1053/j.gastro.2006.12.032

21. Sugerman HJ, DeMaria EJ, Felton WL III, Nakatsuka M, Sismanis A. Increased intra-abdominal pressure and cardiac filling pressures in obesity-associated pseudotumor cerebri. Neurology (1997) 49(2):507-11. doi:10.1212/WNL.49.2. 507

22. Pandolfino JE, El-Serag HB, Zhang Q, Shah N, Ghosh SK, Kahrilas PJ. Obesity: a challenge to esophagogastric junction integrity. Gastroenterology (2006) 130(3):639-49. doi:10.1053/j.gastro.2005.12.016

23. Rieder F, Cheng L, Harnett KM, Chak A, Cooper GS, Isenberg G, et al. Gastroesophageal reflux disease-associated esophagitis induces endogenous cytokine production leading to motor abnormalities. Gastroenterology (2007) 132(1):154-65. doi:10.1053/j.gastro.2006.10.009

24. Kato M, Watabe K, Hamasaki T, Umeda M, Furubayashi A, Kinoshita K, et al. Association of low serum adiponectin levels with erosive esophagitis in men: an analysis of 2405 subjects undergoing physical check-ups. J Gastroenterol (2011) 46(12):1361-7. doi:10.1007/s00535-011-0453-3

25. Nilsson M, Johnsen R, Ye W, Hveem K, Lagergren J. Obesity and estrogen as risk factors for gastroesophageal reflux symptoms. JAMA (2003) 290(1):66-72. doi:10.1001/jama.290.1.66

26. Bernal-Reyes R, Monzalvo Lopez A, Bernal-Serrano M. [Prevalence of gastrointestinal symptoms in overweight and obese subjects: an epidemiologic study on a Mexican population]. Rev Gastroenterol Mex (2013) 78(1):28-34. doi:10.1016/j.rgmx.2012.10.006

27. Hutson WR, Wald A. Obesity and weight reduction do not influence gastric emptying and antral motility. Am J Gastroenterol (1993) 88(9):1405-9.

28. Kim DY, Camilleri M, Murray JA, Stephens DA, Levine JA, Burton DD. Is there a role for gastric accommodation and satiety in asymptomatic obese people? Obes Res (2001) 9(11):655-61. doi:10.1038/oby.2001.89

29. Fysekidis M, Bouchoucha M, Bihan H, Reach G, Benamouzig R, Catheline JM. Prevalence and co-occurrence of upper and lower functional gastrointestinal symptoms in patients eligible for bariatric surgery. Obes Surg (2012) 22(3):403-10. doi:10.1007/s11695-011-0396-z

30. Pourhoseingholi MA, Kaboli SA, Pourhoseingholi A, Moghimi-Dehkordi B, Safaee A, Mansoori BK, et al. Obesity and functional constipation; a communitybased study in Iran. J Gastrointestin Liver Dis (2009) 18(2):151-5.

31. Eslick GD. Prevalence and epidemiology of gastrointestinal symptoms among normal weight, overweight, obese and extremely obese individuals. Gastroenterol Clin North Am (2010) 39(1):9-22. doi:10.1016/j.gtc.2009.12.007

32. Crowell MD, Cheskin LJ, Musial F. Prevalence of gastrointestinal symptoms in obese and normal weight binge eaters. Am J Gastroenterol (1994) 89(3):387-91.

33. Talley NJ, Quan C, Jones MP, Horowitz M. Association of upper and lower gastrointestinal tract symptoms with body mass index in an Australian cohort. Neurogastroenterol Motil (2004) 16(4):413-9. doi:10.1111/j.1365-2982.2004. 00530.x

34. Delgado-Aros S, Camilleri M, Garcia MA, Burton D, Busciglio I. High body mass alters colonic sensory-motor function and transit in humans. Am J Physiol Gastrointest Liver Physiol (2008) 295(2):G382-8. doi:10.1152/ajpgi.90286.2008 
35. Depoortere I. Taste receptors of the gut: emerging roles in health and disease. Gut (2014) 63(1):179-90. doi:10.1136/gutjnl-2013-305112

36. Troke RC, Tan TM, Bloom SR. The future role of gut hormones in the treatment of obesity. Ther Adv Chronic Dis (2014) 5(1):4-14. doi:10.1177/ 2040622313506730

37. Dockray GJ. Gastrointestinal hormones and the dialogue between gut and brain. J Physiol (Lond) (2014) 592(Pt 14):2927-41. doi:10.1113/jphysiol.2014.270850

38. Longstreth GF, Thompson WG, Chey WD, Houghton LA, Mearin F, Spiller RC. Functional bowel disorders. Gastroenterology (2006) 130(5):1480-91. doi:10. 1053/j.gastro.2005.11.061

39. Talley NJ, Phillips SF, Wiltgen CM, Zinsmeister AR, Melton LJ III. Assessment of functional gastrointestinal disease: the bowel disease questionnaire. Mayo Clin Proc (1990) 65(11):1456-79. doi:10.1016/S0025-6196(12)62169-7

40. Cobanoglu C, Moreo P, Warde B. A comparison of mail, fax and web-based survey methods. Int J Market Res (2001) 43(4):441-52.

41. Asch DA, Jedrziewski MK, Christakis NA. Response rates to mail surveys published in medical journals. JClin Epidemiol (1997) 50(10):1129-36. doi:10.1016/ S0895-4356(97)00126-1
Conflict of Interest Statement: The authors declare that the research was conducted in the absence of any commercial or financial relationships that could be construed as a potential conflict of interest.

Received: 08 August 2014; accepted: 16 November 2014; published online: 04 December 2014.

Citation: Huseini M, Wood GC, Seiler J, Argyropoulos G, Irving BA, Gerhard GS, Benotti P, Still C and Rolston DDK (2014) Gastrointestinal symptoms in morbid obesity. Front. Med. 1:49. doi: 10.3389/fmed.2014.00049

This article was submitted to Gastroenterology, a section of the journal Frontiers in Medicine.

Copyright (c) 2014 Huseini, Wood, Seiler, Argyropoulos, Irving, Gerhard, Benotti, Still and Rolston. This is an open-access article distributed under the terms of the Creative Commons Attribution License (CC BY). The use, distribution or reproduction in other forums is permitted, provided the original author(s) or licensor are credited and that the original publication in this journal is cited, in accordance with accepted academic practice. No use, distribution or reproduction is permitted which does not comply with these terms. 